\title{
Exploring the Future of Malawi's Environment Using Scenarios Approach
}

\section{Geoffrey Chavula*, Feston Zambezi, Mathews Tsirizeni, Michael Mmangisa, Yanira Ntupanyama, Kenneth Gondwe, Tawonga Mbale Luka, Sosten Chiotha}

Leadership for Environment and Development-Southern and Eastern Africa (LEAD-SEA), Zomba, Malawi

Email: ${ }^{\star}$ gchavula@gmail.com

How to cite this paper: Chavula, G., Zambezi, F., Tsirizeni, M., Mmangisa, M., Ntupanyama, Y., Gondwe, K., Luka, T.M. and Chiotha, S. (2017) Exploring the Future of Malawi's Environment Using Scenarios Approach. International Journal of Geosciences, 8, 837-856.

https://doi.org/10.4236/ijg.2017.86048

Received: May 31, 2017

Accepted: June 25, 2017

Published: June 28, 2017

Copyright $\odot 2017$ by authors and Scientific Research Publishing Inc. This work is licensed under the Creative Commons Attribution International License (CC BY 4.0).

http://creativecommons.org/licenses/by/4.0/

\begin{abstract}
Discussed in this paper are results of the study that was conducted as part of the process of compiling Malawi's State of the Environment and Outlook Report for the year 2010. The status of the country's economy and the nature of governance were identified as critical drivers, i.e., "critical uncertainties", in determining the future state of the environment in Malawi. Four environmental scenarios were developed, namely: Scenario 1: "Mkaka ndi Uchi", a combination of good economy and good governance; Scenario 2: "Penda Penda", a combination of poor economy and good governance; Scenario 3: "Wafa Wafa", a combination of poor economy and poor governance; and Scenario 4: "Chonchobe/Ndawonera Momwemo", a combination of good economy and poor governance. Each of the four scenarios will be uniquely influenced by the prevailing economic and governance situation in the country, and hence impact differently on Malawi's environment. Economy and Governance were selected as critical determinants out of seven key environmental drivers: demography, governance, social change, economy, environment and climate change, technology, and culture and tradition. From the above listed scenarios, it is only Scenario 1, Mkaka ndi Uchi, which will result in a prosperous Malawi while the rest portend the prevalence of a chaotic situation in the country, more so Scenario 3, the Wafa Wafa scenario.
\end{abstract}

\section{Keywords}

Scenario, Mkaka ndi Uchi, Penda Penda, Wafa Wafa, Chonchobe/Ndawonera Momwemo

\section{Introduction}

The Brundtl and Report [1] stated that all development endeavors should be preceded by a clear understanding of the path to a sustainable future. In reality, mankind's ability to foresee a sustainable development path is obscured by un- 
certainties in a host of variables, including: socioeconomic factors, political dispensations, rule of law, traditional and global economies, demographic trends, changes in consumer behavior, and climate change and climate variability. Traditional approaches to environmental policy planning have failed to effectively describe how these variables interlink to affect natural resource use, and subsequently our society, the environment, and the economy. As such, it was the desire of the researchers to find a more comprehensive approach to current and future environmental planning in Malawi. Using the modeling system developed for the African Environmental Outlook [2], the team of researchers opted to use scenarios to explore conditions that would be conducive to enhancing natural resource stewardship in the country. The advantage of using the "scenarios approach" is that it allows for the exploration of proactive policies and strategies that would ensure that the country is prepared to deal with future eventualities.

UNEP [3] defines scenarios as "descriptions of journeys to possible futures" which reflect different assumptions about how current trends will unfold, how critical uncertainties will play out, and what new factors will come into play. Scenarios include an interpretation of the present, a vision of the future and an internally consistent account of paths from the present to various futures. Ultimately, scenarios are intended to provide better policy or decision support, and stimulate engagement in the process of change [3]. However, scenarios are not predictions, but rather plausible stories of how the future might unfold, based on known information about current trends.

A number of scenario exercises have been carried out in environmental assessments and policy analysis. Some of the notable examples are: Millennium Ecosystems Assessment Report [4], which discusses various outlooks on different issues; IPCC Special Report on Emission Scenarios [5], which highlights four climate change scenarios; World Water Vision [6], which provides information on three global scenarios on water resources; Africa Environment Outlook [2], which discusses four regional scenarios on environment and economy; and UNEP Global Environment Outlook [7], which describes four global scenarios on the environment.

The overall goal of the Malawi environment scenario building process was to present insights into the national outlook, up to the year 2025. Specifically, the process was intended to:

a) Combine qualitative and quantitative information about the future evolution of environmental challenges and opportunities in Malawi;

b) Identify the robustness of environmental policies under different future conditions;

c) Illustrate how alternative policy pathways can achieve environmental targets and aspirations contained in the Malawi Growth and Development Strategy (MGDS), Millennium Development Goals (now replaced by Sustainable Development Goals) and Vision 2020;

d) Describe future alternative states of the environment with/without various policies, thereby illustrating the impact of the society on the natural envi- 
ronment and the need for formulation and implementation of environmental policies, and;

e) Raise awareness about the future relationship between different environmental challenges and threats to the natural environment and human well-being.

\section{Methodology}

The process of scenario building for Malawi's State of Environment and Outlook Report (SOER) of 2010 was done in a participatory and consultative manner. Several stakeholders were involved in the exercise, including: thematic chapter authors of the SOER, officials drawn from Government Ministries and Departments (e.g., Environmental Affairs Department, Ministry of Development Planning and Cooperation, Ministry of Local Government), the academia (e.g., University of Malawi), and members of staff from Leadership for Environment and Development-Southern and Easter Africa (LEAD-SEA). The process commenced with the selection of 2025 as a target year, a decision which was arrived at after taking into consideration the corresponding end-dates of Malawi's Vision 2020, Malawi Growth and Development Strategy (MGDS), and the New Partnerships for Africa's Development (NEPAD) Environmental Action Plan. There was a general consensus among the stakeholders on the selected target year due to the understanding that it would make the State of Environment and Outlook Report relevant to the country's development needs and aspirations in the short and medium term.

Secondly, participants identified key drivers of environmental change in Malawi from a list of drivers shown in Table 1. These were: economic development, demography, governance, environment and climate change, social change, technology, and culture and tradition. From this list of drivers, two highly uncertain drivers with the greatest potential impact on the environment as "critical uncertainties" were selected. A critical uncertainty may be defined as "a driver that is especially important in determining how the future will evolve, but whose future development is highly unpredictable" [7].

The five step procedure highlighted below [7] was adopted in choosing Malawi's critical uncertainties:

a) Consider each driver in turn, and define the range of possible ways it could evolve;

b) Consider the degree of uncertainty in each driver. How much variation is there in the range of possible ways it could evolve? Is there a great deal of uncertainty, or relatively little?

c) Consider the relative importance of each driver into the future. Does the way the driver evolves make a major difference in the vision for the future, or does it make relatively minor difference?

d) Plot each driver on the chart of Importance ( $\mathrm{Y}$ axis) versus Uncertainty (X axis). The further the dot on the $\mathrm{X}$ axis, the greater the uncertainty in how that driver will develop. The further the dot on the $\mathrm{Y}$ axis, the more significant is the impact of the driver; and 
Table 1. Key drivers.

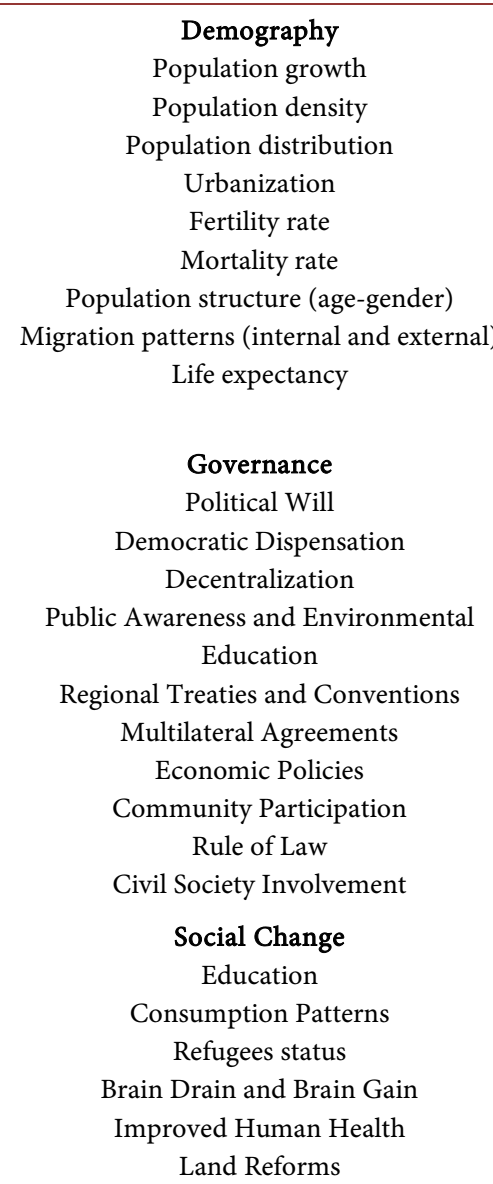

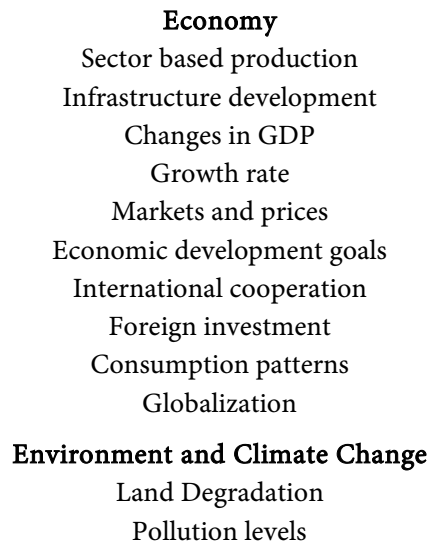

Culture and Tradition

Beliefs, Traditional Ceremonies, Cultural Heritage, Extraction of Medicinal Plants, Religion, Customary Land Tenure and Free-range grazing of livestock

e) Identify drivers that have the highest importance.

Through this process, Economy and Governance emerged as the two most critical uncertainty factors influencing environmental health in Malawi; and were subsequently used in defining scenarios for the country by plotting them on a quadrant in four possible combinations as shown in Figure 1.

The economy axis was defined in terms of change in total production and consumption of goods and services, measured by the Gross Domestic Product. Positive values on the $\mathrm{Y}$ axis indicate high growth in GDP while negative values indicate low or negative growth rates. The Governance (X) axis was defined in terms of political will and commitment at all levels to engage in activities that protect natural resources. This includes the health of democracy and observance of the rule of law. Positive $\mathrm{X}$ values indicate that leaders in government, non-governmental organizations, and civil society organizations are committed to developing appropriate environmental protection policies, strategies and legal instruments, and maintaining adequate capacity to enforce regulations. Through 


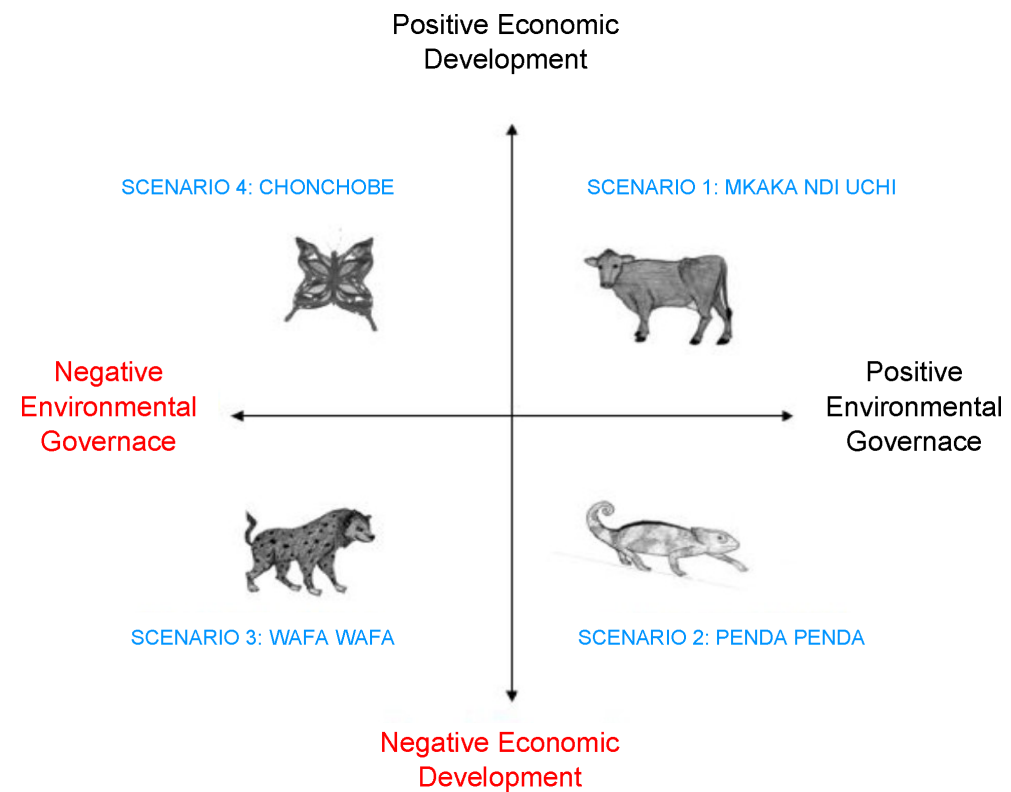

Figure 1. Scenarios for Malawi.

public awareness programmes, individuals, communities and organizations cooperate to support government initiatives to address environmental challenges. As the value of $\mathrm{X}$ becomes negative, government becomes indifferent or even hostile to matters of environmental protection. The society at large is uninformed about environmental challenges facing the nation; as such, there is no concerted effort to protect the environment. In the absence of public awareness campaigns, effective environmental protection regulations and enforcement mechanisms, environmental degradation is unchecked. On communal and publicly held land, a classic "tragedy of the commons" situation develops due to individualistic over-exploitation. In the absence of a regulatory framework, access to and exploitation of the country's natural resources becomes a source of potentially violent conflict.

\section{Results}

The two critical uncertainties interact in four possible combinations (Figure 1), each of which represents a possible environmental scenario for Malawi. These scenarios have been given Chichewa names, a local language in Malawi, with English translations:

Scenario 1-Mkaka ndi Uchi (Milk and honey);

Scenario 2-Penda Penda (Staggering along);

Scenario 3-Wafa Wafa (Beyond redemption); and

Scenario 4-Chonchobe/Ndawonera Momwemo (Survival of the fittest).

Scenario 1 (Mkaka ndi Uchi) depicts a situation in which Malawi experiences good governance and economic prosperity. Such a situation would enable the country attain environmentally sustainable development. This is symbolized by a Cow which is a sign of prosperity as well as good environmental governance, since a cow provides milk for nourishment and dung for the enhancement of soil 
fertility and the production of energy for domestic heating.

Scenario 2 (Penda Penda) describes a situation in which the country experiences good governance but dismal economic growth, resulting in unsustainable development. Under this scenario, environmental protections would not be secure in Malawi. This is symbolized by a chameleon, which exhibits a slow staggering motion, and thus takes a long time to cover a short distance.

Scenario 3 (Wafa Wafa) is the converse of "Mkaka ndi Uchi". It depicts the prevalence of a chaotic situation in Malawi, in which the country experiences both poor economic growth and poor governance. Under this scenario there will be cut-throat competition for the country's over-exploited and dwindling resources. Corrupt individuals will prosper at the expense of the majority of Malawians. The other Chichewa name for this scenario is "Ali ndi mwana agwiritse", literally meaning "hold fast to what you have". This is symbolized by a Hyena, an animal considered to portend bad omen in Malawi.

Scenario 4 (Chonchobe/Ndawonera Momwemo) depicts a situation of similar gravity to Penda Penda. However, the source of instability is poor governance rather than poor economic performance. High economic growth comes at the cost of future prosperity, as resources are unsustainably exploited. Dictators who accumulate wealth and enhance income disparity might emerge under this scenario. This is symbolized by a butterfly which survives on small amounts of nectar.

\subsection{Scenario 1: Sustainable Economic Development and Good Governance (Mkaka ndi Uchi)}

The year is 2025. For the past 15 years, Malawi has experienced unprecedented economic development, characterized by substantial increases in sector based production and vigorous growth in GDP. This economic triumph was a direct result of massive public investment in infrastructure development, which attracted extensive foreign investments, as well as improvements in the performance of the international economy. Successful policy responses to address the problem of overdependence on tobacco for export led to diversification in the agricultural sector and increased off-farm income generating activities. The expansion of the manufacturing and service sectors led to the expansion of the export base of the country with a concomitant improvement in balance of payment.

During this period the country matured as a democracy committed to good governance, with systems in place to enforce environmental policies, strategies and regulations. The political leadership displayed unwavering support for eco-efficient technologies, coupled with impressive improvements in capacity across economic and environmental sectors. This enabled the sustainable exploitation of the country's natural resources for the benefit all sections of the population. The country decisively and effectively responded to critical environmental issues in the priority areas of water, land and agriculture, health and environment, and human settlements, inculcating in the citizenry a culture of eco-efficiency and emphasizing collective responsible for sustainable production 
and consumption. Use of water saving technologies gave impetus to advances in agriculture and other sectors of the economy. Advancements in industrial engineering led to the designing of industrial projects and factories committed to reducing wastes, and reuse and recycling of wastes. Advanced technologies allowed industries to do more with less, thereby using the country's natural resources more efficiently and sustainably.

During this period, there was a dramatic increase in agricultural intensification and productivity, which enabled crop diversification from maize into high value crops for export and to support the domestic manufacturing industry. As a result of intensification, cultivation on marginal lands such as riverbanks and steep slopes was discontinued. Successful reforestation programmes saw a dramatic reversal of the trend in deforestation, reducing soil erosion and improving soil fertility. Energy saving technologies were widely adopted, which reduced dependency on biomass energy and resulted in regeneration of indigenous Miombo forests. Additional renewable energy sources became available, and new sites for hydroelectric generation were developed. This led to a reduction in the economic and environmental cost of electricity at the industrial and domestic level. The urban transportation system experienced a revolution as the use of private cars and minibuses was replaced by rapid mass transit electric trains. This resulted in a substantial decrease in water and air pollution and the emission of greenhouse gases, and a subsequent improvement in the health and well-being of the population. Traffic patterns that use less time and energy were developed (such as roundabouts and overtake lanes), improving pedestrian safety and reducing fossil fuel use.

The advances in eco-efficient designs reduced the environmental impact from a wave of economic development that swept the country. The advances enhanced the benefits that accrued to Malawians from the rapid economic development. The technologies supported the creation of an abundance of well-paying green jobs by both the public and the private sector. Viable and vibrant partnerships were established between the government, private sector, and civil society organizations in developing environmental efficient technologies in all sectors of the economy.

Issues of environmental protection increasingly took a center stage in all short and medium term development policies strategies of the country. The environment became the major thrust for all government supported development programmes designed to spur economic development, achieve greater equity and other social goals. An important aspect of the strategy was the greater involvement of communities in deciding their destiny within the framework of the overall government sustainable development strategy. In this regard, all community led initiatives were conceived to achieve the sustainable development agenda. Community awareness and training programmes opened up new avenues for public dialogue and community empowerment in the management of government and natural resources. The shift in approach from government-led to community-led development resulted in well entrenched decentralized lea- 
dership structures.

Under this scenario, the country experiences a reversal of negative trends in the integrity of the environment and made significant gains in its restoration. Significant gains were also registered in natural resource productivity. Productivity in the agricultural sector was driven by an increase in the use of organic fertilizers and biological pest control approaches. The country's food security situation reached sustainable levels, with smallholder farmers becoming less dependent on subsidized fertilizers and other agro-inputs. Food security was achieved through increased intensification (and so productivity) of maize, bananas, tubers and roots. This was in response to government's deliberate policies and strategies to encourage farmers in different ecological zones to produce crops that offer them a comparative advantage and a change in consumption pattern of the country as whole. The land used for tobacco production shrunk remarkably as government put in place more robust policies and strategies in response to the global anti-smoking campaign that intensified between 2015 and 2020. The drive to diversify the economy saw a shift from over reliance on tobacco as a cash crop to increase in areas growing nontraditional export crops such as pulses and high value export crops such as flowers and vegetables.

Although under this scenario, the demographic pressures eased only slightly as a result of declining fertility rates, the pressure on land resources would have been worse had it not been for the advances in environmental conservation, spear-headed by the land reforms which accorded customary land free-hold status. Intensification of outreach services and preparation and enforcement of village land use plans played a significant role in arresting cultivation on environmentally fragile lands such as river banks, steep slopes and wetlands. This resulted in a remarkable reduction in soil erosion and nutrient loading of the county's drainage system. The country experienced uninterrupted supply of electricity as rivers were less burdened by silt loads and debris washed down from catchment areas.

Under this scenario, the Government of Malawi has put in place measures for conserving biodiversity by adhering to the tenets of the Convention on Biological Diversity (CBD) and the Addis Ababa Principles and Guidelines. As a result, the country has been able to counter factors which have hitherto been responsible for biodiversity degradation in Malawi, namely: high human population growth, over-harvesting, destruction of habitats, agricultural expansion, poverty, invasive alien species, and illegal hunting and trade of biological resources [8].

In the 2013 Annual Economic Report, it was reported that all sectors in the MDG subtheme of "sustainable economic growth" were performing very well, way above the average in achieving indicator targets.

The following observations are noted for the key sectors of the economy:

1) Water

a) There is an increase in demand for water resources in line with improved consumption pattern, however water efficient technologies counter the negative effects of the rising demand for water; 
b) Levels of pollution in river systems are closely monitored, and a strong enforcement regime that the Government has put in place against water pollution is yielding benefits;

c) Cultural practices and traditions are integrated into the overall water management, putting emphasis on combining science and Local Indigenous Knowledge Systems and Practices (LIKSP);

d) Rivers maintain regular flows and ground water recharge is maximized;

e) Advanced technologies lead to better understanding of water resources through research, and facilitates better management of river basins; and

f) Service providers and consumers put into practice water demand management principles and hence there is virtually no loss of water in pipe distribution networks and wastage at the point of use.

2) Land and Agriculture

a) The integrity of the environment gets a major boost from widespread use of agro forestry technologies which leads to improved water holding capacity and increased content of organic matter in soils;

b) The country experiences an improvement in production per unit area through adoption of sustainable farming practices and appropriate technologies;

c) The country achieves self-sufficiency in food on a sustainable basis through increases in maize production and improvements in non-traditional food crops such as bananas and ground provisions;

d) The country has adopted smart agriculture as an adaptive strategy for averting adverse effects of climate change on agricultural production, resulting in improved crop yields and enhanced food security at household level; and

e) Because Malawi has developed the mining and industrial production sectors, which have created off-farm employment opportunities, the amount of land devoted to agriculture has declined drastically. This has given impetus to forest regeneration and arrested soil erosion and land degradation.

3) Health and Environment

a) The adoption of an ecosystems approach to human health has resulted in a reduction in environmentally linked diseases;

b) Intense public awareness results in the phasing out of cultural practices and traditions that fuel the spread of HIV/AIDS and other sexually transmitted diseases;

c) Increase in the health budget improves the health and wellbeing of all Malawians, and results in substantial gains in productivity; and

d) Investment in human resource development in the health sector leads to dramatic reduction in brain drain, hence there is adequate capacity in the country to deal with environmentally related issues.

4) Human Settlements

a) The country's population is steadily moving towards replacement level as a result of decreasing fertility rate brought about by the formulation and implementation of robust and effective population policies; 
b) The rate of urbanization continues to rise but is being better managed with the emergency of vibrant small and medium sized towns;

c) A healthy urban environment has been created through sound investments in housing, waste management and public transport;

d) Pollution is kept under control by the popularization of public transport as a result of the introduction of efficient mass transit systems and cleaner industrial processing systems;

e) There is widespread acceptance of planning controls as the whole country is a planning area;

f) A dramatic increase in the middle class and innovative housing policies lead to an increase of urban population living in high and medium density permanent housing areas with a corresponding decline in people living in unplanned settlements; and

g) Rural planning has been introduced to regulate the settlement and land use patterns of the rural population, which currently stands at over $80 \%$ of the total population.

5) Biodiversity

a) Because the country has reduced its dependence on forest and land resources for the sustenance of rural livelihoods, the country experiences a resurgence of diversity of biological resources, and a recovery of degraded land;

b) Better management of fish and wildlife resources through improved comanagement arrangements results in an increase in fish and wildlife resources in the country;

c) Because of increased intensification of agricultural production, hotspots of rich biological diversity are protected from destruction, thereby promoting biodiversity conservation;

d) The adoption of sustainable harvesting of biological resources and stabilized human population growth enables Malawi to witness an increase in biodiversity; and

e) The Malawi Government has put in place adaptive strategies for climate change that promote biodiversity conservation.

\subsection{Scenario 2: Good Environmental Governance but Environmentally Unsustainable Economic Development (Penda Penda)}

The period towards 2025 was characterized by substantial major strides in the drive for environmental protection and restoration. After successive successful elections, a culture of democracy prevailed in all sections of the society. As a result of the stability that the country enjoyed, the government was able to formulate policies and enforce regulations to correct negative impacts of economic development on the environment. A number of programmes were developed to harness community initiatives to address critical environmental issues. Representative democracy also took root in urban areas, with all grass root structures functioning optimally. The available resources, however, only allowed modest investment in infrastructure, housing and public health. Thus, a substantial sec- 
tion of city dwellers still live in squalid conditions, with no access to basic amenities.

Under scenario 2, the country experienced a modest reversal of the gains recently made in the area of food security, infrastructure improvement and high rate of economic growth. Poverty continued to decline but only in the short term as a result of improvements in agricultural extension programs, targeted agricultural input subsidies. From 2020, it became apparent that the economic development being experienced could not be sustained. The targeted agricultural input subsidy programme was slowly phased out, resulting in a corresponding decline in agricultural productivity, notably maize production. The use of organic manure was not widespread enough to counter the effect of the withdrawal of the fertilizer subsidy programme. This created new challenges in the implementation of environmental protection and restoration measures as the country struggled to feed the ever increasing population. This inevitably led to the opening up vast expanses of land hitherto considered unsuitable for farming.

Despite vigorously pursuing environmental protection policies, it became obvious that this was not being translated into real change and prosperity to the citizenry. Demographic pressure continued as benefits from the family planning services on offer could not be realized in the short term. The population structure is dominated by economically active persons and thus there are more people seeking employment than what the labor market can absorb.

While it is widely acknowledged that strengthening of governance structures is critical for mature democracy, invariably the levels of resources channeled to such institutions do not match with the tasks at hand. Development projects that would bring widespread and equitable prosperity are underfinanced and consequently poverty begins to resurface. Under this scenario, economic development is hampered by unsustainable resource dependence. The implementation of more robust monetary policies that would reduce poverty in the long-term are shelved over concerns that this would trigger inflation.

1) Water

a) Water is widely understood as a finite resource; as a result, water conservation measures are enforced at all levels;

b) Communities are well organized and grass root structures are put in place to promote and enforce water saving technologies. However, due to declining support, these structures begin to crumble, and so do the environmental protection programmes; and

c) The threat of pollution from unsustainable industrial production processes is countered by a strict regime of enforcement of environmental protection regulation.

2) Land and Agriculture

a) Improvement in soil conservation result in an initial improvement in agricultural productivity;

b) Due to the sluggish economic performance, gains in the integrity of the environment are slowly wiped out, and the governance structures begin to col- 
lapse due to underfunding;

c) Soil conservation programmes are either downsized, or discontinued altogether, leading to a slow but steady increase in soil erosion and loss of plant nutrients; and

d) Agricultural input subsidy programmes are overtime withdrawn, adversely affecting the country's per capita food availability.

3) Health and Environment

a) Inadequate funding for the health sector result in increased child mortality and poor maternal health;

b) Environmentally related diseases are on the increase due to the neglect of water and sanitation infrastructure, and the lack of integration of an ecosystems approach to healthcare; and

c) The healthcare delivery system is unable to cope with the increase in the disease burden, and the situation is made worse by resignation of health personnel in search of more lucrative job opportunities outside Malawi.

4) Human Settlements

a) There is general decline in absolute numbers and proportion of households living in unplanned settlements;

b) General decline in the quality of housing but minimum standards are maintained;

c) Industries struggle financially to comply with waste disposal regulations, but due to strict government controls, there is no rampant violation of environmental protection measures; and

d) There is use of unsustainable construction materials in the absence of affordable environmentally friendly technologies.

5) Biodiversity

a) There is a decline in biodiversity as the country continues to depend on forest resources and agricultural production for the sustenance of rural livelihoods;

b) There is a general decline in fish and wildlife resources resulting from poor management of biological resources;

c) Hot spots of rich biodiversity are wiped out as a result of increased agricultural production, with the consequent degradation of biological resources; and

d) Because people do not practice sustainable harvesting of biological resources, there is a substantial decline of biodiversity resources in the country. The problem is compounded by inadequate capacity of the Government of Malawi to develop adaptive strategies for climate change in the biodiversity sector.

\subsection{Scenario 3: Poor Governance and No Economic Prosperity (Wafa Wafa)}

Under this scenario, all the governance and economic development indicators in Malawi paint a very bleak picture of the present and future environmental conditions. It is evident that the country is barely able to stand on its feet as the ma- 
jority of its citizens are severely impoverished and wallow in poverty while a well-connected minority that thrives on corruption is getting richer and richer, albeit at a great cost to the environment and the poor masses. The decentralization drive advocated and vigorously supported by previous successive leaderships has taken a back seat. The system is highly centralized and grossly insensitive to the plight of the poor masses in rural and urban areas of the country. The prevalence of this state of affairs in the country has seen the total collapse of all governance structures while the provisions for the protection of the environment only remain in the statute books, with commitment to enforce these regulations declining to its lowest ebb. The ability to enforce environmental protection regulation is further complicated by rampant corruption which has taken root at all levels of the society.

A combination of demographic pressure and the lack of well-crafted policies and strategies to deal with the upsurge in demand for energy and food has resulted into an unprecedented decline in the integrity of the environment and resource productivity. The population carrying capacity is exceeded in all the districts in the country, resulting in increased deforestation and soil erosion. Cultivation on steep slopes, riverbanks and other marginal lands is on the increase, leading to choking of the country's drainage system with silt and debris washed down from catchment areas. This led to persistent power outages which brought the manufacturing sector to the blink of total collapse. The intermittent supply of electricity resulted in the creation of additional pressure on the country's forest reserves as households depended more and more on fuel wood for cooking and domestic heating. The situation also led to an increase in foreign exchange losses and high commodity prices as businesses heavily relied on diesel generators to satisfy the energy demand.

The food insecurity of the 1990s and early 2000 resurfaced as serious food shortages and soaring prices of basic food items cause untold suffering to the poor masses. The elite took advantage of the food shortage to buy and withhold stocks which resulted in exaggerated food shortages on the market and an escalation of commodity prices. Development projects started in the later 2000s stalled, or were completed at a substandard level due to unscrupulous contractors and contract managers siphoning money to sustain their lavish and elite lifestyles. As the gap between the rich and the poor continued to widen, the poor became increasingly disillusioned and frustrated by empty promises of economic prosperity preached by the leadership. An atmosphere of tension developed between the two classes creating a fertile ground for lawlessness and anarchy. The feeling of helplessness among the poor destroyed the sense of community ownership instilled between 2005 and 2011. People became more individualistic as they focused only on their own survival under the prevailing harsh economic conditions, lending credence to the "Ali ndi mwana agwiritse" warning, literally meaning: "hold fast to what you have". Community environmental protection and restoration projects, such as community woodlots and famer field schools that once flourished in the country, no longer enjoy the support of the commun- 
ities; and have all been abandoned or vandalized.

The population of the country soared as family planning services collapsed due to inadequate funding as the country's developmental partners withdrew their assistance, even to humanitarian causes. The country lost ground on advances made to contain the HIV/AIDS pandemic hence the number of orphaned children increased tremendously from 2015. The demographic pressures in the rural area fuelled rural-urban migration resulting in the proliferation of squatter settlements and further deterioration of the housing conditions of the urban poor because local authorities lack resources to implement long term strategies to deal with the population influx.

It is apparent under this scenario that the Government of Malawi did not put in place measures for conserving biodiversity as stipulated by the Convention on Biological Biodiversity (CBD) and the Addis Ababa Principles and Guidelines. The country dismally failed to conserve biodiversity because of high human population growth, over-harvesting, destruction of habitats, agricultural expansion, poverty, invasive alien species, and illegal hunting and trade of biological resources [8].

1) Water

a) Levels of water pollution are on the increase as there are no appropriate policy responses to deal with the dumping of industrial waste in the country's river systems;

b) Unsustainable use of water resources cause a decline in per capita water availability;

c) The country's capacity to meet its energy needs is highly compromised as a result of siltation and intermittent river flows; and

d) Due to poor community organization, the shortage of water is more acute in rural areas and the majority of the households use unprotected water sources leading to persistent outbreaks of waterborne diseases, particularly cholera, blood-diarrhea, and dysentery; and water washed diseases, such as scabies.

2) Land and Agriculture

a) Unsustainable exploitation of land resources result in unprecedented land degradation;

b) Soils are highly degraded as people have no access to soil conservation technologies;

c) There is no incentive to maximize production because of lack of reliable markets and general decline of commodity prices;

d) Cultivation on marginal lands and areas along river banks is on the increase resulting in perennial flooding of rivers in the country;

e) Extreme weather conditions, fueled by the El Nino and Southern (ENSO) phenomena, set in and famine is a reality to the majority of Malawians who grapple with food shortages; and

f) Conflicts over land for livestock and crop production increases; but neither form of production is sustainable.

3) Health and Environment 
a) Dramatic increase in human population puts enormous pressure on the country's health delivery system and lead to high mortality rates and low life expectancy;

b) Overcrowding and unhealthy living conditions in the urban area fuel the outbreak of diseases;

c) The health delivery system fails to benefit from technological advances in the health sector; as such, the rich seek treatment from outside the country, resulting in foreign exchange losses;

d) Cultural practices that fuel the spread of HIV/AIDs, sexually transmitted diseases, and other communicable diseases are widespread. The belief in witchcraft as an explanation for disease gains prominence; and

e) Poverty related diseases are on the increase due to malnourishment.

4) Human Settlements

a) Rivers in all major industrial cities are choked with toxic industrial waste and the effects on the human population begin to show around 2020;

b) Housing units for average income earners become unavailable to the majority of the city dwellers;

c) There is an emergency of large informal sector upon which the Informal housing sector thrives; and

d) A large informal housing sector emerges, and little attention is paid to minimum health and sanitation standards, leading to frequent outbreaks of communicable diseases.

5) Biodiversity

a) Total collapse of biodiversity resulting from poor management of resources, human population explosion, lack of alternative sources of rural livelihoods. This leaves the country literally bare and vulnerable to erosion because of the removal of vegetation cover;

b) Fish and wildlife resources are very scarce;

c) All hot spots of biodiversity in the country are completely destroyed; and

d) The problem of biodiversity degradation is exacerbated by the vagaries of climate change.

\subsection{Scenario 4: Economic Prosperity but Poor Governance (Chonchobe/Ndawonera Momwemo)}

By 2015, the country economy had fully recovered from the effects of the global economic meltdown and successively achieved double digit GDP growth rate through to 2025. The emergency of new technologies saw rapid expansion in all productive sectors of the economy, driven by profit maximization motive. Productivity gain in the agriculture sector was fuelled by the emergency of high yielding and disease resistant varieties, the introduction of universal agricultural input subsidy programmes by the Government, and improved global commodity prices. To satisfy the ever increasing demand for agricultural products, land under agriculture dramatically increased, extending to environmentally fragile areas. An important aspect of the increase in productivity of the agriculture sec- 
tor was an increasingly important role played by large scale commercial estates. This resulted in the displacement of subsistence farmers by these estates from arable land to less fertile areas, resulting in a wave of rural-urban migration. While the earlier success in the growth of the manufacturing sector resulted in creation of many jobs, the trend started to reverse as the country's natural resources started to dwindle as a result of unsustainable exploitation. Unemployment in the urban areas started to rear its ugly head. Investment into infrastructure development, public health and housing started to decline; and it was no longer difficult to see the signs of urban decay in areas inhabited by the urban poor. The pollution of rivers in the major industrial cities of Blantyre, Lilongwe and Mzuzu was in the increase due to the effluent discharge of toxic industrial wastes. While the regulatory framework for discharge of industrial effluent into the rivers existed, there was no political will to enforce the regulations because of preoccupation with profit maximization drive that existed at the time.

The negative trends in environmental integrity became widespread and affected all aspects of the daily lives of the citizens, yet the government miserably failed to respond to the looming environmental crisis. Increased inflow of nutrients from farmlands resulted in eutrophication of rivers and frequent occurrences of algal blooms. Thus, poor water quality was increasingly becoming a threat to aquatic life while silt and debris had far reaching impact on the country's ability to produce electricity from its hydropower plants to meet energy needs that had increased to unsustainable level. The proportion of urban dwellers living slums and lacking basic amenities was dramatically on the rise again, with attendant outbreaks of waterborne and water washed diseases.

In the absence of functioning grass root environmental governance structure, and with no support being channeled to community led environmental protection and restoration initiatives, the rural landscape was stripped bare of the indigenous forest cover; and even traditional construction materials became scarce. Water resources were worst affected by the neglect, ground water recharge decreased to dangerous levels, and river flow fluctuations between dry and rainy season widened remarkably.

1) Water

a) Pressure on water resources peaks around 2020 due to increase in demand from all productive sectors of the economy and unsustainable use of the resource;

b) The country fails to take advantage of global advances in water efficient technologies;

c) Economic prosperity is under threat as the country is unable to meet its energy requirements from hydropower plants which are performing at half capacity due to irregular river flows; and

d) Water resources suffer from increased effluent discharge of toxic industrial wastes; and its effects on the health of the affected people start to show around 2020.

2) Land and Agriculture 
a) There is an increase in agricultural production for both the domestic and export markets;

b) The motive to maximize production leads to depletion of essential soil nutrients and soil degradation;

c) Extensive farming coupled with uncontrolled use of pesticides result in loss of soil cover, and pollution of rivers and lakes;

d) There is loss of agricultural land due to the expansion of urban areas; and

e) The collapse of governance structures lead to expansion of farmlands onto environmentally fragile environment, leading to increase in soil erosion and loss of biodiversity;

3) Health and Environment

a) Waterborne and water washed diseases are on the increase and yet no attention is paid to calls to incorporate Eco health;

b) Increase in the volume of waste chokes the already overstretched waste management system, and its effects on the health of the affected people surfaces around 2022; and

c) Gains in improvement of the health status of the Malawian society start to diminish as a result of lack of environmental governance structures.

4) Human Settlements

a) There is an increased air pollution from industries and vehicles;

b) There is loss of prime agricultural land to accommodate the ever increasing rate of urbanization;

c) Majority of the urban poor live under squalid conditions in unplanned settlements and environmentally fragile areas;

d) There is increased storm flow and downstream flooding as a result of increased surface run-off from paved areas;

e) Rivers are choked with toxic industrial and domestic effluents leading to a spreading diseases;

f) There is a general mushrooming of sub-standard and poorly designed buildings in cities and towns;

g) There is increased stress from worsening traffic congestion; and

h) The major cities experience unprecedented rural-urban migration because small and medium towns are neglected.

5) Biodiversity

a) There is a decline in biodiversity as the country continues to depend on forest resources and agricultural production for the sustenance of rural livelihoods;

b) There is a general decline in fish and wildlife resources resulting from poor management of biological resources;

c) Hot spots of rich biodiversity are wiped out as a result of increased agricultural production, with the consequent degradation of biological resources; and

d) Because people do not practice sustainable harvesting of biological resources, there is a drastic decline of biodiversity resources in the country. The prob- 
lem is compounded by inadequate capacity of the Government to develop adaptive strategies for climate change in the biodiversity sector.

\subsection{The Inter-Linkages and Policy Lessons}

The four scenarios highlighted in the preceding discussion help to illustrate how alternative policy pathways can achieve environmental targets in the Sustainable Development Goals and Malawi Growth and Development Strategy. The scenario exercise helps us to understand how environmental governance and economic development combine to either enhance or damage our environment. Through the scenario building process, it is clear that whatever pathway we opt to the year 2025, there will be environmental impacts along the way. Table 2 shows the relative qualitative and quantitative assumptions of the trends of the drivers under each Scenario. Thus, there are a number of actions that could be undertaken in order to reduce the associated negative impacts.

\section{Conclusions}

The Malawi Environmental and Outlook Report have come up with four possible future scenarios for the country as follows:

Scenario 1 (Mkaka ndi Uchi) — a combination of sustainable economic development and good environmental governance, with the following characteristics:

a) A positive investment climate largely due to improvements in infrastructure and presence of good corporate governance structures;

b) Higher growth rates as a result of increase in human capital;

Table 2. Relative qualitative and quantitative assumptions of the trends of the drivers in each scenario.

\begin{tabular}{|c|c|c|c|c|}
\hline \multirow[b]{2}{*}{ Driver/Scenario Issue } & \multicolumn{4}{|c|}{ Qualitative/Quantitative Assumption on Future Trends } \\
\hline & $\begin{array}{c}\text { Scenario } 1 \\
\text { Mkaka ndi Uchi }\end{array}$ & $\begin{array}{c}\text { Scenario } 2 \\
\text { Penda Pends }\end{array}$ & $\begin{array}{l}\text { Scenario } 3 \\
\text { Wafa Wafa }\end{array}$ & $\begin{array}{c}\text { Scenario } 4 \\
\text { Ndaonera Momwemo }\end{array}$ \\
\hline \multicolumn{5}{|l|}{ Demography } \\
\hline Economy & & & & \\
\hline Governance & & & & \\
\hline \multicolumn{5}{|c|}{ Environment and Climate Change } \\
\hline \multicolumn{5}{|l|}{ Social Change } \\
\hline \multicolumn{5}{|l|}{ Technology } \\
\hline Culture and Tradition & & & & \\
\hline
\end{tabular}


c) Preservation of livelihoods through implementation of adaptation policies for climate change;

d) Advances in technologies for green energy and creation of green in jobs in the private sector;

e) A steady and significant decline in the proportion of the people living below the national poverty line achieved through several measures, including increased productivity of agriculture, and development of sustainable secondary and tertiary industries; and

f) Existence of vibrant community environmental governance structure, leading to successful implementation of numerous communities led environmental protection and regeneration programmes.

Scenario 2 (Penda Penda) - a combination of good environmental governance and unsustainable economic development, with characteristics as follows:

a) Limited infrastructure improvements, with modest effect on the economy;

b) The economy grows but not in a sustainable way as eco-friendly technologies are not fully embraced; and

c) The integrity of the environment remains the same or slightly declines due to underfunding of environmental protection and regeneration programmes.

Scenario 3 (Wafa Wafa) - a combination of poor environmental governance and economic downturn. This is the worst case scenario with the collapse of the governance structures and a national economic disaster. Some of the specific characteristics of this scenario are:

a) Rapid population growth, resulting in a huge labor force;

b) Rising unemployment and under employment fuel poverty among the majority of Malawians;

c) Economic growth stagnates due to lack of lack of improvements in infrastructure and unfavorable economic policies;

d) Degradation of natural resource base due to poor governance lead to increasing food insecurity;

e) There is rampant corruption in the country at all levels of the society; and

f) Technology deteriorates without an economic or government economic framework, leading to more unemployment and more poverty.

Scenario 4 (Chonchobe/Ndawonera Momwemo) - a combination of economic prosperity under poor environmental governance. The characteristics of this scenario may be summarized as follows:

a) Increased pressure on the natural resource base due rapid increase in human population;

b) Decreasing human capital limits economic growth in the long term;

c) High consumer demand act as a driver for the economy but environmental protection and restoration ranks very low on government priority list, resulting in long term adverse effect on the economy as the resource base is degraded;

d) Infrastructure starts to deteriorate as a result of lack of maintenance and the awarding of contracts through corruption; and 
e) There are economic incentives to develop the economy. However, these technologies are not guided by government regulations and do not necessarily target the most pressing environmental problems.

Each one of the scenarios presents challenges and opportunities similar to those highlighted in Sustainable Development Goals being implemented through the Malawi Growth and Development Strategy (MGDS) and Vision 2020. Malawi will have to deal with the challenges in order to meet the targets set in the

MGDS. The Malawi Vision 2020 gives strategic options in order to address the environmental challenges.

In order to move Malawi forward and meet the challenges ahead, we will have to reorganize ourselves and embrace "lessons from the future". Malawi will have to formulate and implement, swiftly and in a decisive manner, a set of policies and strategic actions in order to achieve sustainable economic development. From the scenarios lessons, the options include: investment in infrastructure development, particularly the energy sector, to boost production; focus on shifting away from primary industries, and create incentive programmes for environmentally-friendly business start-ups; invest in human capital to build economic resource for the future; and to build genuine political will at the highest level to support appropriate institutional and legal reforms for deepening of decentralization.

\section{References}

[1] World Commission on Environment and Development (1987) Our Common Future (Commonly Referred to as "The Brundtland Report"), Oxford University Press.

[2] UNEP (2006) Africa Environment Outlook 2: Our Wealth, Our Future. United Nations Environment Programme (UNEP), Nairobi.

[3] UNEP (2002) Global Environment Outlook-3: Past, Present and Future Perspectives. Earthscan, London.

[4] Millennium Ecosystem Assessment (2005) Ecosystems and Human Well-Being. Island Press, Washington DC.

[5] IPCC (2007) A Special Report on Emission Scenarios. Geneva, Switzerland.

[6] World Water Council (2000) World Water Vision. Earthscan Publications Ltd., UK.

[7] UNEP (2007) Fourth Global Environment Outlook: Environment for Development. United Nations Environment Programme (UNEP), Nairobi.

[8] Environmental Affairs Department (2010) Malawi's Implementation of the Convention on Biological Diversity. Government of Malawi, Lilongwe. 
Submit or recommend next manuscript to SCIRP and we will provide best service for you:

Accepting pre-submission inquiries through Email, Facebook, LinkedIn, Twitter, etc. A wide selection of journals (inclusive of 9 subjects, more than 200 journals)

Providing 24-hour high-quality service

User-friendly online submission system

Fair and swift peer-review system

Efficient typesetting and proofreading procedure

Display of the result of downloads and visits, as well as the number of cited articles Maximum dissemination of your research work

Submit your manuscript at: http://papersubmission.scirp.org/

Or contact ijg@scirp.org 